\title{
SEMBLANZA
}

\section{Homenaje al Doctor Rodrigo Guerrero Velasco}

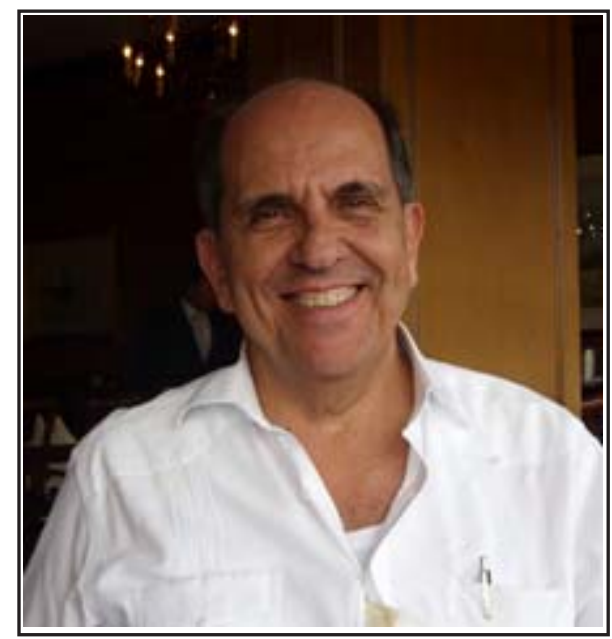

Palabras leídas en el homenaje al doctor Rodrigo Guerrero Velasco dentro del marco del $X$ Simposio de Investigaciones en Salud de la Universidad del Valle el día miércoles 22 de octubre de 2008

Hablar del doctor Rodrigo Guerrero Velasco es remitirse a una de las personas que como ciudadano distinguido, siempre ha estado comprometido con su ciudad, su departamento y con Colombia. Además como profesional y docente, ha sido uno de los pioneros en el desarrollo de investigaciones, en la creación de nuevos paradigmas educativos y en la generación de estrategias y políticas públicas que posibilitan una mejor convivencia entre los ciudadanos.

Es médico egresado de la Universidad del Valle, con un doctorado con honores en Salud Pública de la Universidad de Harvard. Se ha desempeñado en forma sobresaliente en numerosos puestos de comando de la salud y el bienestar:

- Fue director de la hoy Escuela de Salud Pública de la Universidad del Valle donde imprimió su espíritu de epidemiólogo.

- Como director del Hospital Universitario del Valle fortaleció la vinculación con nuestra Alma Mater.

- Fue Secretario de Salud de Cali durante la alcaldía de Rodrigo Escobar Navia, de tan grata recordación.

- Director de la Fundación Carvajal.

- Decano de nuestra Facultad de Salud, en donde entre otras cosas lideró un programa entre educación y demografía como respuesta a la formación en esta área de nuestros escolares.

- Rector de la Universidad del Valle.

- Alcalde mayor de Cali, por elección popular, en el período 1992-1995.

En ejercicio de sus funciones como primera autoridad municipal, era frecuente verlo con un pañuelo blanco anudado en los extremos, que usaba para protegerse del sol; visitaba vecindarios y comunas para interactuar con sus conciudadanos, en especial con los más empobrecidos.

La ciudad lo vivió y valoró como un mandatario honesto, comprometido, que se reunió e interactuó con todos los caleños, conociendo a fondo sus dificultades, expectativas y problemas, para las cuales ofreció salidas y respuestas novedosas que se concretaron en programas sociales de largo aliento.

Vale la pena resaltar el proceso de implantación del monitoreo, registro y evaluación permanentes que estableció con el programa DESEPAZ, en donde, además de involucrar a todas las dependencias de la alcaldía en un programa de desarrollo y paz, logró convocar y comprometer a todas las fuerzas militares y de policía, cuerpos de investigación del Estado (fiscalía, procuraduría, DAS) en una estrategia de prevención de violencia y educación para la convivencia, modelo que 
ha sido adoptado en otras ciudades del país y del continente. Con este modelo, logró reducir en Cali las muertes violentas con acciones desde la ley semi-seca y el desarme, entre otras.

Su espíritu quijotesco lo llevó a irse de su Colombia querida para iniciar en la OPS el programa de manejo y control de la violencia y sus consecuencias, lo cual lo hizo vincular con el BID y donde, obviamente, consiguió fondos para los programas respectivos en el país. Regresa y funda CISALVA, el centro de investigaciones sobre este tema que bajo su liderazgo y valiosa asesoría y con la continuidad de sus sucesores, se ha consolidado como un centro de excelencia a nivel internacional.

Su enfoque visionario logró interesar a distintos organismos de cooperación internacional en soluciones para uno de los problemas más graves de la ciudad, como lo es la violencia, poniendo como base la estrategia ya implementada con éxito en Cali.

Al dejar la Alcaldía, y en respuesta a otro de los acuciantes problemas de violencia en el campo, se puso en la tarea de crear Vallenpaz, organización que ha brindado alternativas de convivencia, desarrollo y paz a una población agobiada por el conflicto armado.

Desde la academia, como profesor de epidemiología y de salud pública, abrió los ojos y enseñó a no «tragar entero» a nuestros estudiantes de pre y postgrado, donde él se deleitaba más con los discípulos de pregrado, porque considera que son los semilleros de la buena medicina. Nos enseñó a leer artículos científicos y a escribirlos; nos inculcó el gusto y la mirada crítica del epidemiólogo; nos hizo entender que la medicina es más que llamarse médico, donde su modelo era ese excelente médico que era su padre, patriarca y bonachón, pero sabio en el manejo clínico de sus pacientes.

Rodrigo ha realizado valiosos aportes con más de medio centenar de artículos sobre medicina y epidemiología, prevención de violencia, seguridad ciudada- na, sistemas de información, publicados en revistas nacionales e internacionales; fundó y dirigió por muchos años a Colombia Médica, hoy la principal revista médica colombiana, escalafonada en primera categoría en Colciencias y recientemente aceptada en el Instituto de Información Científica (ISI) base de datos bibliográficos donde sólo llegan las revistas de excelencia.

Su libro de epidemiología ha servido de guía no sólo a nuestros egresados, sino a estudiantes de otros países de Latinoamérica y que después de 25 años de publicado, se mantiene como texto básico en la enseñanza de esta disciplina. Ha posicionado la epidemiología en áreas en las cuales estas metodologías no se utilizaban, mostrando en ellas evidentes resultados.

Después de trece años, Rodrigo ha regresado a la arena pública como concejal del municipio en este período del actual cabildo, donde seguramente desde esta posición seguirá contribuyendo a la ciudad con programas que mejoren la convivencia y la seguridad ciudadana y que permitan retornar a Cali como la ciudad acogedora, cívica y sobresaliente en el concierto de Colombia.

Seguramente se me quedan muchas cosas en el tintero, pero del doctor Guerrero se pueden decir tantas cosas, porque además de poseer una inteligencia privilegiada que lo ha hecho destacarse en la vida académica y en la actividad pública, goza también de una capacidad extraordinaria para el humor y las relaciones interpersonales.

Disfrutar de su amistad y de su creativo humor nos ha hecho la vida más agradable y humana.

Dios te guarde, Rodrigo.

Guillermo Llanos Bejarano, MD Editor General Revista Colombia Médica e-mail: guillanos@yahoo.com 